\title{
Preferential Reinnervation of Motor Nerves by Regenerating Motor Axons
}

\author{
Thomas M. E. Brushart \\ Departments of Orthopaedics and Neurology, Johns Hopkins Hospital, and The Raymond M. Curtis Hand Center, \\ Baltimore, Maryland 21218
}

\begin{abstract}
Regeneration of axons into inappropriate distal nerve branches may adversely affect functional recovery after peripheral nerve suture. The degree to which motor axons reinnervate sensory nerves, and vice versa, has not been determined. In these experiments, HRP is used to quantify the sensory and motor neurons that reinnervate sensory and motor branches of the rat femoral nerve after proximal severance and repair. Motoneurons preferentially reinnervate the motor branch in juveniles and adults, even if the repair is intentionally misaligned or a gap is imposed between proximal and distal stumps. A specific interaction thus occurs between regenerating motor axons and the Schwann cell tubes that lead to the motor branch. This interaction is independent of mechanical axon alignment.
\end{abstract}

Functional recovery is often incomplete or absent after suture of transected mammalian peripheral nerve. Regeneration of proximal axons into inappropriate distal pathways has long been recognized as a possible mechanism for this failurc (Langlcy and Hashimoto, 1917; Sunderland, 1978). The specificity of axon regeneration after peripheral nerve lesions has largely been investigated within sensory or motor systems. Studies intermingling or crossing these systems have focused on end organ reinnervation rather than on pathway selection (Langley and Anderson, 1904; Weiss and Edds, 1945; Zalewski, 1970). Regenerating motor axons could enter Schwann cell tubes that lead to sensory branches and be directed to sensory end organs. Similarly, sensory axons could be led to motor endplates. Not only would these axons fail to establish functional contacts, they could exclude appropriate axons from the pathways they occupy. Despite the potentially dramatic effect of this misdirection, the extent to which it actually occurs has not previously been determined (Lundborg et al., 1986). These experiments quantify the sensory and motor neurons regenerating across a proximal nerve suture into pathways leading to terminal sensory and motor branches. The rat femoral nerve was cut and repaired proximally at a level where sensory and motor axons intermingle. HRP was later applied distally, at a level where the nerve has divided into sensory and motor branches, to identify the

Received July 7, 1987; revised Sept. 22, 1987; accepted Sept. 23, 1987.

This work was supported by Grant 378-85 of the Orthopaedic Research and Education Foundation. I wish to thank Mr. Phillip Kessens for technical assistance, Dr. Alan Kimball for statistical analyses, Dr. Donald Price for providing laboratory space, Ms. Ann Deckert for artwork, and Drs. John Griffin and Cheryl Kitt for reading the manuscript.

Correspondence should be addressed to Thomas M. Brushart, Greater Chesapeake Hand Specialists, 1400 Front Avenue, Lutherville, MD 21093.

Copyright (C) 1988 Society for Neuroscience $0270-6474 / 88 / 031026-06 \$ 02.00 / 0$ neurons reinnervating the selected branch. Age and mechanical alignment of the nerve stumps were varied to determine their relative importance to any specificity with which sensory and motor branches might be reinnervated.

\section{Materials and Methods}

Experiments were performed on the femoral nerves of female SpragueDawley rats (Fig. 1) under Chloropent anesthesia (Dodge Laboratories; $3 \mathrm{ml} / \mathrm{kg}$ ). Six experimental groups each contained 25 animals: adult (1214 weeks, $250 \mathrm{gm}$ ), juvenile ( 3 weeks, $50 \mathrm{gm}$ ), adult rotation, juvenile rotation, adult gap, and juvenile gap. In adult and juvenile groups the proximal femoral nerves were severed bilaterally and precisely realigned with 11-0 nylon sutures under $40 \times$ magnification. In both rotation groups the distal stump was rotated $90^{\circ}$ clockwise on the right and counterclockwise on the left to oppose equivalent portions of the nerve in both limbs, and then was sutured in place with 11-0 nylon. Adult and juvenile gaps were maintained at $1 / 2 \mathrm{~mm}$ by suturing the proximal and distal stumps within silicon tubing (Dow Corning). Animals were reexplored at 2 weeks, and those with disrupted suture lines or a change in the interstump gap were excluded from the study.

Eight weeks were allowed for reinnervation of the distal branches. One sensory branch and the opposite motor branch, randomly determined, were then severed and exposed to 15\% HRP (Sigma VI) in distilled water for $45 \mathrm{~min}$. Forty-eight hours later, the animals were deeply anesthetized and perfused through the left ventricle with onequarter strength Karnovsky's fixative in $0.1 \mathrm{~m}$ Sorensen's phosphate buffer, followed by $15 \%$ sucrose in $0.1 \mathrm{M}$ buffer (Mesulam, 1982). The lumbar spinal cords and sensory ganglia were removed, and the ganglia embedded in albumin-gelatin. Tissues were cut at $80 \mu \mathrm{m}$ on a freezing microtome and reacted with $\mathrm{H}_{2} \mathrm{O}_{2}$ and tetramethyl benzidine to demonstrate HRP within neurons (Mesulam, 1982). Sections were then serially mounted and counterstained with neutral red. HRP-labeled neurons were counted at $40 \times$ by an observer unaware of which branch had received HRP. The presence of split cells in adjacent sections was corrected for by the method of Abercrombie (1946). Data were collected from the first 20 animals to successfully complete the experiment in each group. Each of the 6 groups was then characterized by 4 means: the mean sensory and mean motoneuron counts labeled from the motor branch, and the mean sensory and mean motoneuron counts labeled from the sensory branch. Reinnervation of sensory and motor branches was compared within each group by separate paired $t$ test analyses for sensory and motoneuron counts. A repeated-measures analysis of variance was attempted, but was not possible because of the lack of homogeneity of variance among groups.

Control experiments were performed to characterize the femoral nerve model and assess its reliability. In 4 normal adults, HRP was applied to one motor branch and the contralateral sensory branch. HRP-labeled sensory and motor neurons were then counted to define the neuron population normally innervating the sensory and motor branches. The possibility of HRP labeling through an unintended pathway was tested for in 2 adults that had regenerated after proximal femoral nerve suture. Contralateral sensory and motor branches were exposed to HRP, after which they were ligated proximally to block the central transport of HRP. The distribution of motor branch axons within the proximal femoral nerve was determined in 2 adults and 2 juveniles by labeling the axons with HRP-WGA (Brushart, 1986). Bilateral motor branches were exposed to $15 \%$ HRP-WGA for $2 \mathrm{hr}$. Twelve hours were allowed for central transport of the enzyme, after which the animals were deeply 


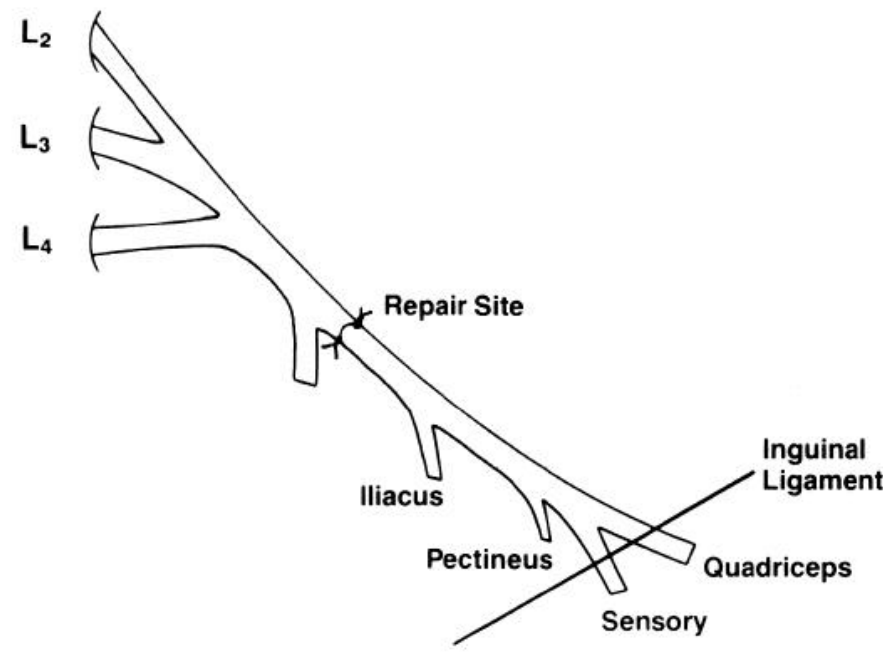

Figure 1. Ventral view of the rat left femoral nerve. The femoral nerve receives $\mathrm{L} 2, \mathrm{~L} 3$, and $\mathrm{L} 4$ contributions and innervates the iliacus and pectineus muscles before dividing into a motor branch to the quadriceps and a terminal sensory branch. The sensory branch includes the saphenous nerve as well as local cutaneous innervation. The nerve is sutured proximally as it exits the lumbosacral plexus; HRP is applied distally to the sensory or quadriceps motor branch after they have passed beneath the inguinal ligament.

anesthetized and perfused with fixative (Mesulam, 1982). The femoral nerves were then embedded in albumin-gelatin and $80 \mu \mathrm{m}$ frozen sections cut at $2 \mathrm{~mm}$ intervals throughout the proximal nerve.

The femoral nerve model was further characterized by defining the myelinated axon populations of the motor and sensory branches. The motor and sensory branches of 2 adults and 2 juveniles were embedded in Epon-Araldite, sectioned at $1 \mu \mathrm{m}$, and photographed at $200 \times$. Myelinated axons were counted from photographic prints (final magnification, $1370 \times$ ), and a Houston Instruments Hi-Pad digitizing tablet was interfaced with an Apple II + computer and appropriate software (R\&M Biometrics, Nashville, TN) to determine the total myelinated axoplasmic area for each branch.

\section{Results and Discussion}

Exposure of 4 normal motor branches to HRP labeled a mean of 338 motoneurons (range, 309-365) and 476 sensory neurons (range, 437-524). In contrast, Peyronnard et al. (1986) labeled a mean of 598 motoneurons ( 345 alpha, 253 gamma) from the rat quadriceps nerve, also using HRP. These investigators counted neurons from serial reconstructions of $40 \mu \mathrm{m}$ sections; the volume of material in our experiments necessitated counting from $80 \mu \mathrm{m}$ sections and correcting for split cells. The similarity of our mean control count (338) to their alpha count (345) suggests that our criteria for excluding fragments of proximal dendrites also excluded many gamma motoneurons. Exposure of 4 sensory branches labeled a mean of 1659 sensory neurons (range, 1489-2174) and no motoneurons.

Ligation of exposed sensory or motor branches eliminated neural labeling altogether, confirming that HRP could be reliably confined to the intended pathway in the femoral nerve model. HRP-WGA axon tracing revealed that axons confined to the motor branch distally were dispersed at proximal levels in both juveniles and adults (Fig. 2). Proximal nerve repair would thus provide most regenerating axons with access to a mosaic of sensory and motor Schwann cell tubes in the distal stump.

Myelinated axon counts were consistently greater in the sensory branch, with little difference between adults and juveniles (Table 1). Mean myelinated axoplasmic area, by contrast, was greater in the motor branch by a factor of 1.73 in adults and 1.63 in juveniles. The ideal model for this experiment would present regenerating axons with 2 groups of Schwann cell tubes, which differed only in their sensory/motor identity. However, the inherent size discrepancy between motor and sensory axons makes this impossible. The rat femoral nerve model, with more, smaller axons in the sensory branch and fewer, larger axons in the motor branch, presented the best compromise between several mammalian models studied (T. M. Brushart, unpublished observations).

Experimental data are summarized in Figures 3 and 4. More motoneurons were labeled from the motor branch than from the sensory branch in all groups. The difference between the 2 branches was highly significant ( $p \leq 0.0002)$ except in the adult animals in which a gap had been imposed between the proximal and distal nerve stumps $(p=0.029)$. Sensory neuron labeling was significantly greater from the sensory branch in all groups except for the well-aligned adult repairs. However, it is difficult to know if the sensory findings are biologically significant. The sensory branch contains more myelinated axons than the motor branch, and could thus receive more innervation on a random basis. The abnormal reinnervation of the motor branch by many more sensory axons than it normally contains could also reflect random behavior by sensory axons. Discussion will therefore be limited to motor reinnervation.

Preferential reinnervation of the motor branch could be (1) a generalized response shared by all axons, (2) the result of

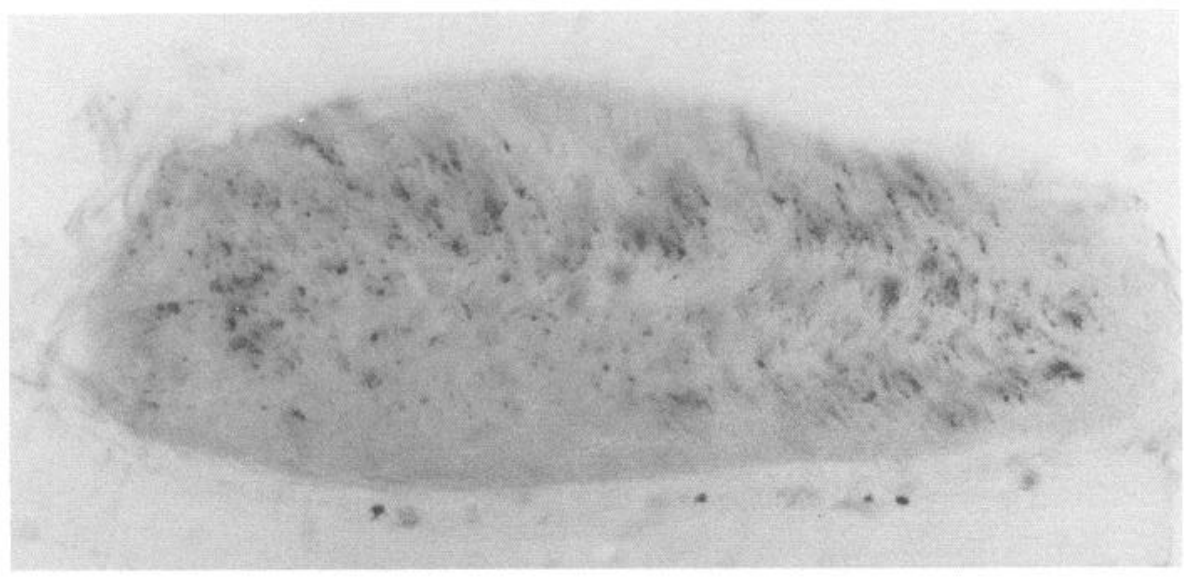

Figure 2. Cross section of the proximal femoral nerve at the repair site. Axons of the motor branch have been labeled with HRP-WGA and are dispersed throughout the nerve. Eighty micron section photographed at $80 \times$. 
Table 1. Microarchitecture of the rat femoral nerve

\begin{tabular}{lll} 
& Adult & Juvenile \\
\hline $\begin{array}{l}\text { Motor branch } \\
\text { Myelinated axon number }\end{array}$ & 1230 & \\
& $(1161-1271)$ & $(1251$ \\
Total axoplasmic area $\left(\mu \mathrm{m}^{2}\right)$ & 25,326 & 12,263 \\
& $(23,568-27,236)$ & $(10,406-14,035)$ \\
Sensory branch & 1672 & 1586 \\
Myelinated axon number & $(1378-1795)$ & $(1550-1632)$ \\
& 14,653 & 7505 \\
Total axoplasmic area $\left(\mu \mathrm{m}^{2}\right)$ & $(12,715-15,577)$ & $(6772-8281)$
\end{tabular}

Both femoral nerves of 2 adult $(250 \mathrm{gm})$ and 2 juvenile $(50 \mathrm{gm})$ Sprague-Dawley rats were embedded in Epon-Araldite and sectioned at $1 \mu \mathrm{m}$. Sections were photographed at $200 \times$. Myelinated axons were counted from photographic prints (final magnification, 1370 $\times$ ), and a Houston Instruments $\mathrm{Hi}-\mathrm{Pad}$ digitizing tablet was interfaced with an Apple II + computer and appropriate software (R\&M Biometrics, Nashville, TN) to determine the total axoplasmic area for each branch. The mean and range are presented for each group of 4 determinations. Myelinated axon counts varied little with age, and were always greater in the sensory branch. Axoplasmic area, in contrast, was greater in the motor branch by a factor of 1.73 in adults and 1.63 in juveniles.

surgical alignment of axons in the proximal and distal cut surfaces of the nerve, (3) a specific interaction between regenerating motor axons and Schwann cell tubes leading to the motor branch. If a preference for motor Schwann cell tubes could guide regeneration of both sensory and motor axons, one would expect reinnervation of the motor branch by equal proportions of the total motor and sensory neuron populations. The finding that motor axons preferentially reinnervate the motor branch, while sensory axons favor the sensory branch, makes a generalized attraction to the motor branch seem extremely unlikely. Specificity produced by surgical alignment of axons should be proportional to the accuracy of repair. Even though sensory and motor axons were dispersed throughout the cross section of the nerve, exact alignment of proximal and distal stumps could approximate individual sensory or motor axons. However, an intentional misrotation of $90^{\circ}$ had little effect on the outcome of motor reinnervation in adults or juveniles. Preferential motor reinnervation thus appears to be independent of mechanical axon alignment. A specific interaction between motor axons and Schwann cell tubes leading to the motor branch therefore remains the most likely possibility.

The mechanism of preferential motor reinnervation cannot be precisely determined from the data presented here. Possibilities include (1) neurotropism: regenerating axons are guided to appropriate Schwann cell tubes by diffusible factors, (2) specific recognition: axons sample Schwann cell tubes and selectively adhere to those with particular surface properties, (3) neurotrophism: axons enter Schwann cell tubes randomly, but mature only in appropriate tubes or after making appropriate end organ contact.

Neurotropic guidance of peripheral axon regeneration was first postulated by Ramon y Cajal (1928). After refutation by Weiss and Taylor (1944), the Theory of Neurotropism was revived by Lundborg et al. (1982), who demonstrated that the distal nerve stump could influence both the orientation and growth of regenerating peripheral axons. Politis et al. (1982) showed this effect to be directed by cells in the distal stump and mediated by diffusible factors, and Kuffler (1986) found directed axon growth to precede target contact. Evidence consistent with the action of neurotropism has also been obtained from tissue culture and embryonic manipulations. Sensory neurites ascend gradients of NGF (Gunderson and Barrett, 1979), and are selectively attracted to appropriate targets in cocultures with either central (Crain and Peterson, 1982) or peripheral (Lumsden and Davies, 1983) nervous tissue. In the chick embryo, reversal of spinal cord segments or moderate limb shifts does not prevent motor axons from reaching appropriate targets, even if unique pathways are created to do so (Lance-Jones and Landmesser, 1980, 1981).

Specific recognition contributes to pathway selection in lower animals (Bastiani et al., 1986), but little evidence currently exists for specific recognition of Schwann cell tubes by regenerating mammalian axons (Scherer and Easter, 1984). However, it has been suggested that Schwann cells (Keynes, 1987) or Schwann cell basal laminae (Lundborg et al., 1986) may preserve clues to their previous axonal associations that could be identified by regenerating axons. The ability of regenerating motor axons to recognize synaptic basal lamina (Sanes et al., 1978; Glicksman and Sanes, 1983), coupled with evidence that sensory and motor
Figure 3. Motoneuron counts resulting from application of HRP to the femoral motor (open bars) and sensory (stippled bars) branches after repair of the proximal femoral nerve. More motoneurons were labeled from the motor branch in all groups. The difference between motor and sensory branches was highly significant $(p \leq 0.0002)$ except in the adult gap group $(p=0.029)$

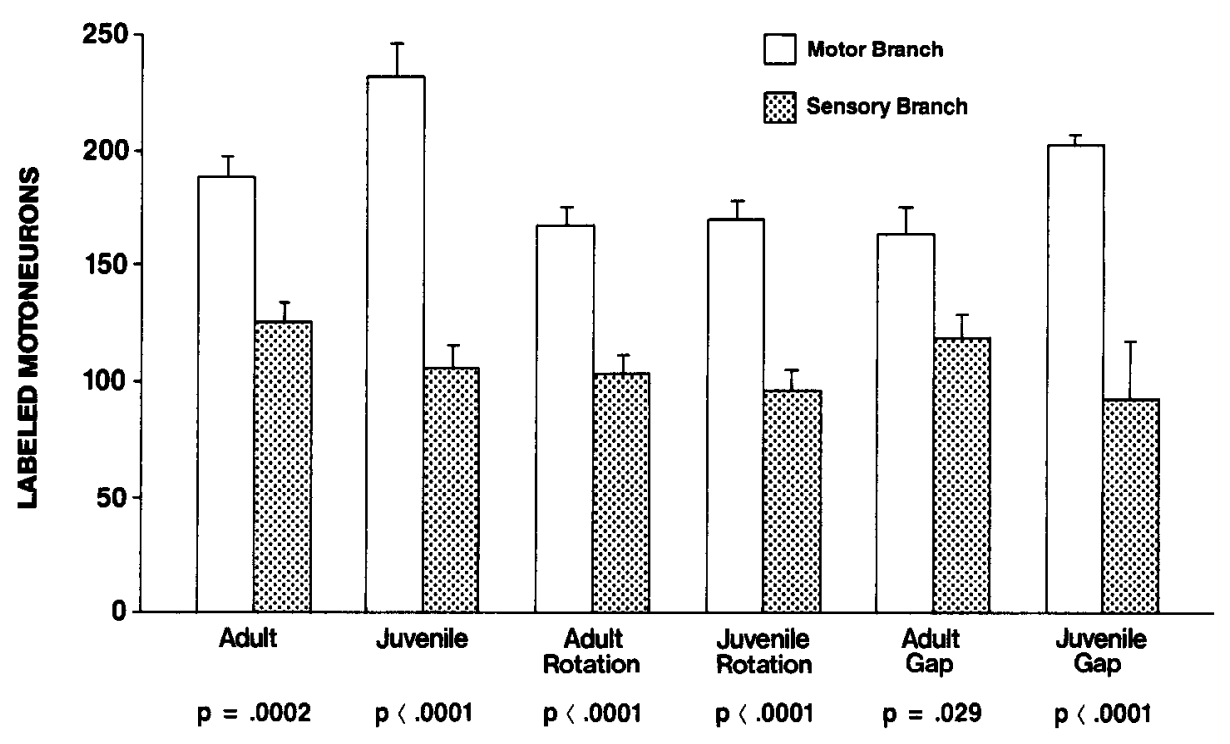




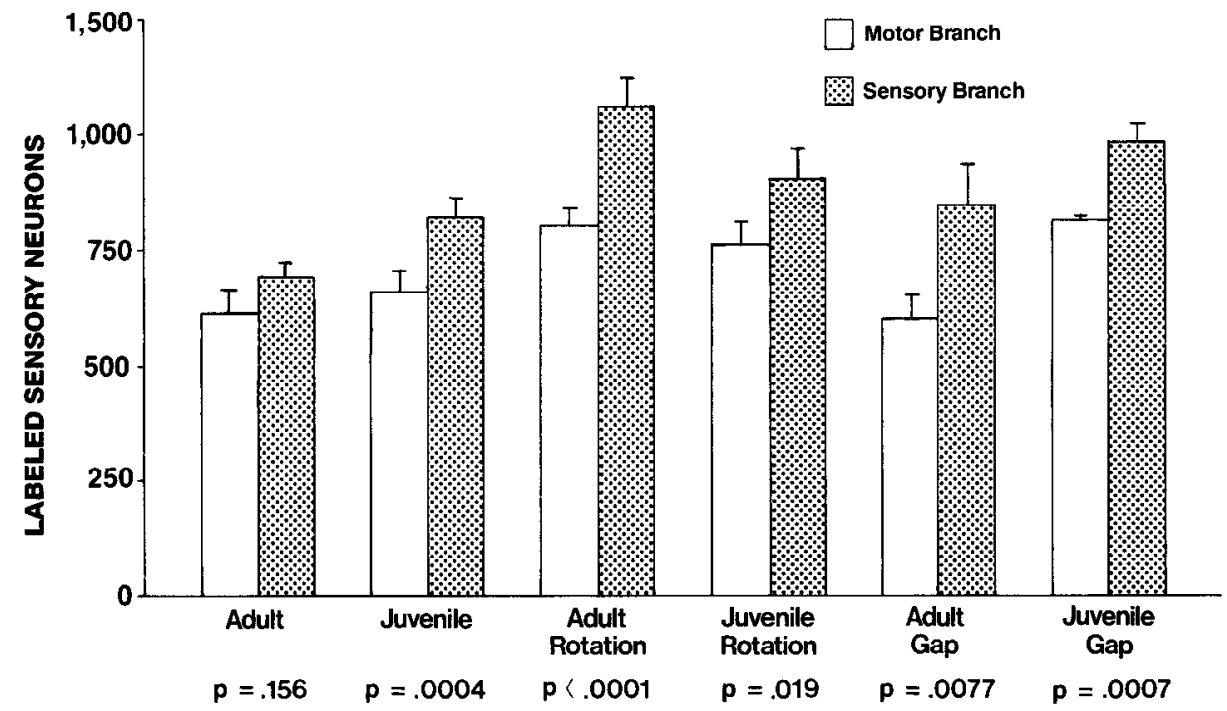

Figure 4. Sensory neuron counts resulting from application of HRP to the femoral motor (open bars) and sensory (stippled bars) branches after repair of the proximal femoral nerve. Significantly more sensory neurons were labeled from the sensory branch in all groups except for adult repairs. axons differ in their surface glycoconjugates (Borges and Sidman, 1982), should encourage further investigation of this possibility.

Neurotrophic activity has been well documented in the peripheral nervous system. Soluble growth factors have been found in peripheral nerve segments (Richardson and Ebendal, 1982; Windebank and Poduslo, 1986) and homogenates (Riopelle et al., 1981; Millaruelo et al., 1986) and have been produced by Schwann cells in culture (Abrahamson et al., 1986; Assouline et al., 1987). Fluid from enclosed nerve gaps contains growth factors for sympathetic, sensory, and spinal cord neurons that are thought to be distinct agents (Longo et al., 1983). Both innervated and denervated muscle contain neurotrophic factors for neurites in culture (Smith and Appel, 1983; Nurcombe et al., 1984).

Selective motor reinnervation was more prominent in juveniles than in adults. The possible significance of this difference could not be determined because of the lack of homogeneity of variance among groups. The juvenile femoral model was, however, compared with the adult to rule out an anatomical bias. Increased selectivity could result from (1) a higher number of axons in the juvenile motor branch, (2) an increase in axoplasmic area in the motor branch relative to the sensory branch, or (3) greater localization of motor branch axons within the proximal femoral nerve. However, there was no significant difference between adults and juveniles on these parameters. Motoneuron death, another potentially selective factor in young animals, is completed in rats before 3 weeks of age (Janjua and Leong, 1984; Oppenheim, 1986). Possible juvenile advantages could include more rapid axon regeneration (Black and Lasek, 1979; Pestronk et al., 1980) or more extensive motor axon branching (Jenq and Coggeshall, 1985), allowing earlier or more extensive sampling of the distal environment. The observation that preferential motor reinnervation is age-related could prove to be clinically relevant. The results of peripheral nerve surgery in children are superior to those in adults (Onne, 1962; Almquist and Eeg-Olofsson, 1970); the difference has been attributed to an age-related aptitude for compensatory central reorganization (Almquist et al., 1983). However, preferential motor reinnervation could also be a factor, implicating both central and peripheral mechanisms.

The specificity of mammalian peripheral nerve regeneration can be examined in an hierarchical framework, proceeding from gross through progressively finer discriminations. Tissue specificity has been demonstrated by Lundborg et al. (1986) and Mackinnon et al. (1986); axons will grow towards other nerve rather than tendon, muscle, or granulation tissue. Within the peripheral nervous system, selectivity can occur at the spinal root (Wigston and Sanes, 1982) and nerve trunk (Politis, 1985) levels. Sensory/motor discrimination was suggested by experiments in a Y-tube model (Brushart and Seiler, 1987), and is here confirmed to be a powerful determinant of peripheral nerve regeneration. The topography of reinnervation has been examined in great detail within both sensory and motor systems. Sensory axons regenerating after nerve transection do not restore their original innervation pattern (Horch, 1979), and the dorsal horn projections of reinnervated tributary nerves expand to resemble those of the entire parent nerve trunk (Brushart et al., 1981). Similarly, the topography of motor innervation is not restored after section of adult peripheral nerves (Bernstein and Guth, 1961; Brushart and Mesulam, 1980; Mizuno ct al., 1980), though meticulous alignment improves the accuracy of reinnervation at the fascicular level (Brushart et al., 1983). In juvenile rats, however, topographical correspondence of motoneuron pools with the periphery is restored after section of the intercostal (Hardman and Brown, 1987) and facial (Aldskogius and Thomander, 1986) nerves. The finest level of discrimination involves recognition of specific sensory or molor end organs. Regenerating cutaneous sensory axons either reinnervate appropriate receptors or induce them to regenerate in their previous locations (Burgess and Horch, 1973; Horch, 1979); sensory reinnervation of muscle is less specific (Banks et al., 1985). Motor axons reinnervate fast and slow twitch muscle fibers randomly under most circumstances (Miledi and Stefani, 1969; Gillespie et al., 1986), though specificity may be present in special situations (Hoh, 1975; Foehring et al., 1986). Muscle spindles may be reinnervated by alpha motoneurons after nerve section (Brown and Butler, 1974), but reinnervation by skeletofusimotor neurons appears to predominate (Scott, 1987).

Specificity at the tissue (Lundborg et al., 1986; Mackinnon et al., 1986), spinal root (Wigston and Sanes, 1982), and nerve trunk (Politis, 1985) levels requires the creation of special circumstances for its detection. Preferential motor reinnervation, by contrast, shapes the outcome of routine peripheral nerve suture. Furthermore, the factors responsible for this phenom- 
enon are of sufficient magnitude to partially overcome the axonal disorganization imposed by stump misalignment or an interstump gap. The ability to discriminate between sensory and motor branches is of additional importance because of its position near the top of the specificity hierarchy, where the populations of axons that enter tributary nerves are determined. Progressively finer discriminations would be useless were the appropriate end organ choices unavailable in a particular tributary nerve. The specificity of sensory/motor reinnervation is not, however, absolute. Though motor axons preferentially reinnervate the motor branch, many have entered the sensory branch in these experiments. An even greater proportion of regenerating sensory axons have entered the motor branch, suggesting that sensory axon behavior may be more random. Definition of the mechanism of preferential motor reinnervation and its augmentation, especially in adults, could thus potentially improve the prognosis of injury to nerves containing both sensory and motor axons.

\section{References}

Abercrombie, M. (1946) Estimation of nuclear population from microtome sections. Anat. Rec. 94: 239-247.

Abrahamson, I. K., P. A. Wilson, and R. A. Rush (1986) Production and transport of endogenous trophic activity in a peripheral nerve following target removal. Dev. Brain Res. 27: 117-126.

Aldskogius, H., and L. Thomander (1986) Selective reinnervation of somatotopically appropriate muscles after facial nerve transection and regeneration in the neonatal rat. Brain Res. 375: 126-134.

Almquist, E., and O. Eeg-Olofsson (1970) Sensory-nerve-conduction velocity and two-point discrimination in sutured nerves. J. Bone Joint Surg. 52A: 791-796.

Almquist, E. E., O. Smith, and L. Fry (1983) Nerve conduction velocity, microscopic, and electron microscopy studies comparing repaired adult and baby monkey median nerves. J. Hand Surg. 8: 406410 .

Assouline, J. G., P. Bosch, R. Lim, I. S. Kim, R. Jensen, and N. J. Pantazis (1987) Rat astrocytes and Schwann cells in culture synthesize nerve growth factor-like neurite-promoting factors. Dev. Brain Res. 31: 103-118.

Banks, R. W., D. Barker, and H. G. Brown (1985) Sensory reinnervation of muscles following nerve section and suture in cats. J. Hand Surg. 10B: 340-344.

Bastiani, M. J., S. du Lac, and C. S. Goodman (1986) Guidance of neuronal growth cones in the grasshopper embryo. I. Recognition of a specific axonal pathway by the pCC neuron. J. Neurosci. 6: 35183531.

Bernstein, J. J., and L. Guth (1961) Nonselectivity in establishment of neuromuscular connections following nerve regeneration in the rat. Exp. Neurol. 4: 262-275.

Black, M. M., and R. J. Lasek (1979) Slowing of the rate of axonal regeneration during growth and maturation. Exp. Neurol. 63: 108119.

Borges, L. F., and R. L. Sidman (1982) Axonal transport of lectins in the peripheral nervous system. J. Neurosci. $2 ; 647-653$.

Brown, M. C., and R. G. Butler (1974) Evidence for innervation of muscle spindle intrafusal fibers by branches of alpha motoneurons following nerve injury. J. Physiol. (Lond.) 238: 41-42.

Brushart, T. M. (1986) The central course of digital axons within the median nerve of Macaca mulatta. Soc. Neurosc. Abstr. 12: 108.

Brushart, T. M., and M.-M. Mesulam (1980) Alteration in connections between muscle and anterior horn motoneurons after peripheral nerve repair. Science 208: 603-605.

Brushart, T. M., and W. A. Seiler (1987) Selective reinnervation of distal motor stumps by peripheral motor axons. Exp. Ncurol. 97: 289-300.

Brushart, T. M., E. W. Henry, and M.-M. Mesulam (1981) Reorganization of muscle afferent projections accompanies peripheral nerve regeneration. Neuroscience 6: 2053-2061.

Brushart, T. M., E. C. Tarlov, and M.-M. Mesulam (1983) Specificity of muscle reinnervation after epineurial and individual fascicular suture of the rat sciatic nerve. J. Hand Surg. 8: 248-253.
Burgess, P. R., and K. W. Horch (1973) Specific regeneration of cutaneous fibers in the cat. J. Neurophysiol. 36: 101-114.

Crain, S. M., and E. R. Peterson (1982) Selective innervation of target regions within fetal mouse spinal cord and medulla explants by isolated dorsal root ganglia in organotypic co-cultures. Dev. Brain Res. 2: 341-362.

Foehring, R. C., G. W. Sypert, and J. B. Munson (1986) Properties of self-reinnervated motor units of medial gastrocnemius of cat. I. Long-term reinnervation. J. Neurophysiol. 55: 931-965.

Gillespie, M. J., T. Gordon, and P. R. Murphy (1986) Reinnervation of the lateral gastrocnemius and soleus muscles in the rat by their common nerve. J. Physiol. (Lond.) 372: 485-500.

Glicksman, M. A., and J. R. Sanes (1983) Differentiation of motor nerve terminals formed in the absence of muscle fibers. J. Neurocytol. 12: 661-671.

Gunderson, R. W., and J. N. Barrett (1979) Neuronal chemotaxis: Chick dorsal root axons turn toward high concentrations of nerve growth factor. Science 206: 1079-1080.

Hardman, V. J., and M. C. Brown (1987) Accuracy of reinnervation of rat intercostal muscles by their own segmental nerves. J. Neurosci. 7: 1031-1036.

Hoh, J. F. Y. (1975) Selective and non-selective reinnervation of fasttwitch and slow-twitch rat skeletal muscle. J. Physiol. (Lond.) 251: 791-801.

Horch, K. (1979) Guidance of regrowing sensory axons after cutaneous nerve lesions in the cat. J. Neurophysiol. 42: 1437-1449.

Janjua, M.Z., and S. K. Leong (1984) Organization of neurons forming the femoral, sciatic, common peroneal and tibial nerves in rats and monkeys. Brain Res. 310: 311-323.

Jenq, C.-B., and R. E. Coggeshall (1985) Numbers of regenerated axons in tributary nerves following neonatal sciatic nerve crush in rat. Neurosci. Lett. 61: 43-48.

Keynes, R. J. (1987) Schwann cells during neural development and regeneration: Leaders or followers? Trends Neurosci. 10: 137-139.

Kuffler, D. P. (1986) Isolated satellite cells of a peripheral nerve direct the growth of regenerating frog axons. J. Comp. Neurol. 249: 57-64.

Lance-Jones, C., and L. Landmesser (1980) Motoneurone projection patterns in the chick hindlimb following early partial reversals of the spinal cord. J. Physiol. (Lond.) 302: 581-602.

Lancc-Joncs, C., and L. Landmcsser (1981) Pathway selection by embryonic chick motoneurons in an experimentally altered environment. Proc. R. Soc. Lond. [Biol.] 214: 19-52.

Langley, J. N., and H. K. Anderson (1904) The union of different kinds of nerve fibers, J. Physiol. (Lond.) 31: 365-391.

Langley, J. N., and M. Hashimoto (1917) On the suture of separate nerve bundles in a nerve trunk and on internal nerve plexuses. $J$. Physiol. (Lond.) 51: 318-345.

Longo, F. M., S. D. Skaper, M. Manthorpe, L. R. Williams, G. Lundborg, and S. Varon (1983) Temporal changes of neuronotrophic activities accumulating in vivo within nerve regeneration chambers. Exp. Neurol. 81:756-769.

Lumsden, A. G., and A. M. Davies (1983) Earliest sensory nerve fibers are guided to peripheral targets by attractants other than nerve growth factor. Nature 306: 786-788.

Lundborg, G., L. Dahlin, N. Danielson, A. Johanneson, and H. Hansson (1982) Regenerating nerve fibers in preformed mesothelial chambers: Influence of the distal segment of a transected nerve on growth and direction. In Clinical Applications of Biomaterials, A. Lee, T. Albrektsson, and P. Branemark, eds., pp. 323-329, Wiley, Chichester, England.

Lundborg, G., L. Dahlin, N. Danielsen, and A. K. Nachemson (1986) Tissue specificity in nerve regeneration. Scand. J. Plast. Recon. Surg. 20: 279-283.

Mackinnon, S. E., A. L. Dellon, G. Lundborg, A. R. Hudson, and D. A. Hunter (1986) A study of neurotrophism in a primate model. J. Hand Surg. 11A: 888-894.

Mesulam, M.-M. (1982) Tracing Neural Connections with Horseradish Peroxidase, Wiley, New York.

Miledi, R., and E. Stefani (1969) Non-selective re-innervation of slow and fast muscle fibers in the rat. Nature 222: 569-571.

Millaruelo, A. I., M. Nieto-Sampedro, J. Yu, and C. W. Cotman (1986) Neurotrophic activity in the central and peripheral nervous systems of the cat. Effects of injury. Brain Res. 374: 12-20.

Mizuno, N., M. Uemura-Sumi, K. Matsuda, Y. Takeuchi, M. Kume, and R. Matsushima (1980) Non-selective distribution of hypoglos- 
sal nerve fibers after section and resuture: $A$ horseradish peroxidase study in the cat. Neurosci. Lett. 19: 33-37.

Nurcombe, V., M. A. Hill, K. L. Eagleson, and M. R. Bennett (1984) Motor neuron survival and neuritic extension from spinal cord explants induced by factors released from denervated muscle. Brain Res. 291: 19-28.

Onne, L. (1962) Recovery of sensibility and sudomotor activity in the hand after nerve suture. Acta Chir. Scand. (Suppl. 300): 1-69.

Oppenheim, R. (1986) The absence of significant postnatal motoneuron death in the brachial and lumbar spinal cord of the rat. J. Comp. Neurol. 246: 281-286.

Pestronk, A., D. B. Drachman, and J. W. Griffin (1980) Effects of aging on nerve sprouting and regeneration. Exp. Neurol. 70:65-82.

Peyronnard, J. M., L. F. Charron, J. Lavoie, and J. P. Messier (1986) Motor, sympathetic and sensory innervation of rat skeletal muscles. Brain Res. 373: 288-302.

Politis, M. J. (1985) Specificity in mammalian peripheral nerve regeneration at the level of the nerve trunk. Brain Res. 328: 271-276.

Politis, M. J., K. Ederle, and P. S. Spencer (1982) Tropism in nerve regeneration in vivo. Attraction of regenerating axons by diffusible factors derived from cells in distal nerve stumps of transected peripheral nerves. Brain Res. 253: 1-12.

Ramon y Cajal, S. (1928) Degeneration and Regeneration of the Nervous System, Oxford U. P., London.

Richardson, P. M., and T. Ebendal (1982) Nerve growth activities in rat peripheral nerve. Brain Res. 246: 57-64.

Riopelle, R. J., R. J. Boegman, and D. A. Cameron (1981) Peripheral nerve contains heterogeneous growth factors that support sensory neurons in vitro. Neurosci. Lett. 25: 311-316.
Sanes, J. R., L. M. Marshall, and U. J. McMahan (1978) Reinnervation of muscle fiber basal lamina after removal of myofibers. J. Cell Biol. 78: $176-198$.

Scherer, S. S., and S. S. Easter (1984) Degenerative and regenerative changes in the trochlear nerve of goldfish. J. Neurocytol. 13: 519565 .

Scott, J. J. A. (1987) The reinnervation of cat muscle spindles by skeletofusimotor axons. Brain Res. 401: 152-154.

Smith, R. G., and S. H. Appel (1983) Extracts of skeletal muscle increase neurite outgrowth and cholinergic activity of fetal rat spinal motor neurons. Science 219: 1079-1081.

Sunderland, S. (1978) Nerves and Nerve Injuries, 2nd Ed., Churchill Livingston, New York.

Weiss, P., and M. V. Edds (1945) Sensory-motor nerve crosses in the rat. J. Neurophysiol. 30: 173-193.

Weiss, P., and A. C. Taylor (1944) Further experimental evidence against neurotropism in nerve regeneration. J. Exp. Zool. 95: 233 257.

Wigston, D. J., and J. R. Sanes (1982) Selective reinnervation of adult mammalian muscle by axons from different segmental levels. Naturc 299: 464-467.

Windebank, A. J., and J. F. Poduslo (1986) Neuronal growth factors produced by adult peripheral nerve after injury. Brain Res. 385: 197200.

Zalewski, A. A. (1970) Effects of reinnervation on denervated skeletal muscle by axons of motor, sensory, and sympathetic neurons. Am. J. Physiol. 219: 1675-1679. 